\title{
Chapter 5 \\ Thinking Dispositions for Teaching: Enabling and Supporting Resilience in Context
}

\author{
Sharon McDonough and Amanda McGraw
}

\begin{abstract}
Preparing pre-teachers for an increasingly challenging teaching profession is a complex work and requires teacher educators to engage in the careful design of both programmes and professional learning opportunities. This chapter explores how an explicit focus on thinking dispositions that enable effective teaching are developed in a Master of Teaching (Secondary) programme. This programme, delivered on-site at a secondary school, included carefully constructed teaching opportunities to support development of thinking dispositions. Ways of thinking and the impact they have on feelings, actions and beliefs will be examined along with how the implementation of our thinking dispositions framework supports the development of resilience in challenging teaching and learning contexts.
\end{abstract}

Keywords Thinking dispositions - Initial teacher education - Resilience • Site-based teacher education

\subsection{Introduction}

Preparing pre-service teachers (PSTs) for an increasingly challenging teaching profession is a complex work and requires teacher educators to engage in the careful design of both programmes and professional learning opportunities. In our Master of Teaching (Secondary) programme, we have an explicit focus on thinking dispositions that enable teachers to activate relevant knowledge, understand situations and direct their strategic abilities (Ritchhart 2002). Through carefully constructed teaching opportunities in partnership schools, we illuminate certain ways of thinking and explore the ways they inform learning and teaching. In this chapter, we examine how the implementation of our thinking dispositions framework in conjunction with the use of the Building Resilience in Teacher Education (BRiTE) (https://www.brite.

S. McDonough $(\bowtie) \cdot$ A. McGraw

Federation University, Ballarat, VIC, Australia

e-mail: s.mcdonough@federation.edu.au

A. McGraw

e-mail: a.mcgraw@federation.edu.au 
edu.au/) modules (see Chap. 3) supports the development of resilience in challenging teaching and learning contexts. We discuss the features of university-led, site-based teacher education and explore how a focus on thinking dispositions and resilience in practical contexts can assist in preparing PSTs for navigating the complexity of their future careers.

\subsection{Enabling and Supporting Resilience in Context: Dispositions and Learning to Teach}

Learning to teach is a complex journey that requires PSTs develop both professional and personal skills that enable them to cope with the challenges that they will encounter. The 2014 report of the Teacher Education Ministerial Advisory Group (TEMAG) identified that "beginning teachers have responsibility for student learning from their first day in the classroom" (p. 34), and therefore need to be "classroom ready". Being classroom ready involves much more than having the technical skills to teach; however, with Brandenburg and Gervasoni (2016) contending that PSTs who are classroom ready "must also have a deep understanding of the contextual factors, personal discourses and emotions that shape their professional self" (p. 117). Developing understandings of pedagogical practices, the influence of contextual factors on teaching, and of the emotional skills and capacities that impact on professional practice is a highly complex work. It requires that teacher educators provide meaningful and authentic contexts in which PSTs can begin to develop their professional teaching selves and identities.

This complexity of learning to teach is widely recognised in the literature, with PSTs experiencing a range of challenges during their teacher education programme, including managing student and classroom behaviour and the demands of everyday classroom life (Mies and Knipe 2018); being evaluated and observed (Väisänen et al. 2018); managing employment, financial stress, and coping with the workload (Grant-Smith and Gillett-Swan 2017); and difficulties associated with navigating relational challenges and feelings of alienation (Buckworth 2017). There is a diverse range of skills, capacities and dispositions required to be effective teachers, with initial teacher education programmes providing a platform for the development of these skills. Through initial teacher education, PSTs can begin to develop proactive strategies and resources that will enable them to cope with, and be resilient in the face of multiple challenges. 


\subsubsection{Developing Resilience Through Initial Teacher Education}

The notion of resilience has become prevalent in both academic and popular literature, yet despite this, there is contestation around the nature of resilience and the contexts in which resilience is demonstrated (Baggio et al. 2015; Hazel 2018; Mansfield et al. 2012; Pooley and Cohen 2010). While popular definitions of resilience might include the idea of "bouncing back" from a challenge or adversity, Pooley and Cohen (2010) propose a new definition of resilience as "the potential to exhibit resourcefulness by using available internal and external resources in response to different contextual and developmental challenges" (p. 34). Central to definitions of resilience is the concept of a challenge or adverse situation, along with successful coping, adaptation and learning (Baggio et al. 2015; Hazel 2018; Pooley and Cohen 2010). We, like Mansfield, Beltman, Broadley, and Weatherby-Fell (2016), regard resilience as a process, as this framing acknowledges that resilience is not a static or fixed trait, but rather is fluid and dynamic.

We draw on a social-ecological model of resilience (Mansfield et al. 2016) that explores processes of resilience within social, relational and organisational contexts. Such views of resilience enable the identification of the personal and contextual resources (Mansfield et al. 2016) that support resilience. In considering the types of personal resources that might support resilient outcomes, Mansfield et al. (2012) argue that "a teacher working in a classroom may require a very different range of skills and dispositions and supporting factors" (p. 358) than someone working in other professions. Fostering resilience enables teachers to respond to the "everyday challenges of the profession, grow and thrive throughout their career" (Mansfield et al. 2016, p. 212), with resilience among teachers associated with commitment and enthusiasm in the profession (Day and Gu 2014). Despite the recognition of the important role that personal and contextual resources play in supporting resilience, there is less literature identifying how teacher education might take advantage of opportunities to build skills and strategies among PSTs that support resilient outcomes (Hazel 2018; Mansfield et al. 2016). In this work, we examine the way that thinking dispositions might both support effective teaching and become personal resources to support resilience in context.

\subsubsection{Dispositions for Thinking and Teaching}

There has been an increased focus, both in Australia and internationally, on the role of dispositions in effective teaching, with some countries, such as the United States, requiring that teacher educators formally assess dispositions as part of accreditation requirements. Despite the increased prevalence of discourses about the sorts of dispositions required for effective teaching, there is a lack of consensus in the literature about the nature of dispositions, and of how they are developed, demonstrated and 
assessed (Diez 2007; McGraw et al. 2016). At times, the term disposition appears to be used interchangeably with terms like characteristics, attitudes or traits. This lack of specificity around the nature of dispositions contributes to the complexity of embedding them within teacher education programmes, and of examining how they might enable effective teaching. While some suggest that the term disposition implies a tendency towards particular actions or behaviours (Freeman 2007), we are interested in examining dispositions as tendencies towards certain ways of thinking.

Costa and Kallick (2000) view dispositions as intellectual resources, arguing that they assist in addressing complex challenges and problems. In an era where there is increasing uncertainty, ambiguity, stress and complexity, Costa and Kallick (2014) argue dispositions that can act as mental and emotional resources, are essential. Others suggest that dispositions are linked to the quality of students' learning and argue that the development of dispositions ought to be the key focus in educational contexts (Perkins and Ritchhart 2004; Riveros et al. 2012). Ritchhart (2002) advocates the notion that intellectual character "can be understood only in terms of the thinking dispositions that give it shape and meaning" (p. 19). Thinking dispositions, such as reflective and critical thinking and having an open mind, are seen as examples that enable greater understanding of self, the contexts we inhabit, and which also activate strategic action in challenging situations (Entwistle 2012). Rather than drawing on work which positions dispositions as "internal attributes or psychological characteristics" (Bair 2017, p. 223), we hold that "dispositions have cognitive, emotional, social and moral dimensions" (McGraw and McDonough 2019, p. 519). We are interested in how an explicit focus on thinking dispositions might enable effective teaching, and act as a resource for supporting resilience in the context of learning to teach. In order to explore this, we have embedded a thinking dispositions framework into our Master of Teaching (Secondary) programme, and we introduce the key features of both the framework and the programme in the following section of the chapter.

\subsection{Our Context: University-Led, Site-Based Teacher Education}

Our 18-month accelerated Master of Teaching (Secondary) programme has a focus on university-led, site-based teacher education. Site-based teacher education programmes are those in which PSTs have sustained engagement, exposure and immersion in sites of practice, with university courses delivered on-site in schools for on-campus students (McGraw et al. 2017; Zeichner 2012). Within the literature, there is also a focus on, and use of the term, practice-based teacher education, with Jenset (2018) arguing that practice-based teacher education is conceptualised in a variety of ways including those models that have increased fieldwork, periods of internship, and connections between fieldwork and coursework. Vartuli, Snider 
and Holley (2016) argue that teacher education that is practice-based, "offers experiences for candidates to begin to understand the complexities of teaching and integrate knowledge from learning and developmental theories into practice" (p. 503). As a key element of some practice-based approaches to teacher education, being immersed in school sites is a key way for PSTs to gain insight into the complexities that Vartuli et al. (2016) describe and to experiment with applying theoretical understandings to practice.

Site-based teacher education requires the establishment of on-going partnerships with schools. As an integral aspect of our partnership with a large local secondary college in our regional setting, we have a designated teaching space for teacher education classes in the school. Being located in the school setting means that we can strategically integrate opportunities for teaching, professional inquiry and reflective practice into university classes and assessment. Our site-based context enables us to be responsive in our teaching as we observe PSTs in action and engage with them in reflective dialogue prior to, in the midst of, and immediately after, teaching experiences. It also offers us a unique opportunity to investigate the impact of our focus on thinking dispositions on PSTs' practice — and on their capacity to be resilient—which is the focus of this chapter. Before examining our research project, we describe the thinking dispositions framework and explain why we wonder about its connection to teacher resilience.

\subsubsection{A Key Feature of the Programme: The Thinking Dispositions Framework}

As a key feature of our Master of Teaching programme, we have developed and embedded a framework of thinking of dispositions that we see as "essential in the discipline of education and for learning in higher education contexts" (McGraw et al. 2016, p. 195), and that inform effective teaching and learning. Based on a review of research as well as discussions between school partners and teacher educators, the framework was developed, trialled and finally embedded in the Master of Teaching programme. Each disposition includes descriptors which highlight what the disposition can look like in teaching and learning contexts. We aim to explicitly examine the dispositions in classes; explore, model and reflect upon them in contexts; enable PSTs to demonstrate them in assessment contexts; and to enhance the dispositions through feedback. Francis et al. (2018) argue that "functional conceptual incoherence" (p. 121) is found across teacher education programmes when staff have differing agendas or enact conceptual visions in diverse ways. The thinking dispositions framework (Fig. 5.1) enables the programme team to have a shared vision and language for modelling, discussing and assessing thinking dispositions and provides a sense of coherence across the programme.

We have become increasingly interested in how site-based teaching and learning experiences provide opportunities to activate and purposefully build the key thinking 


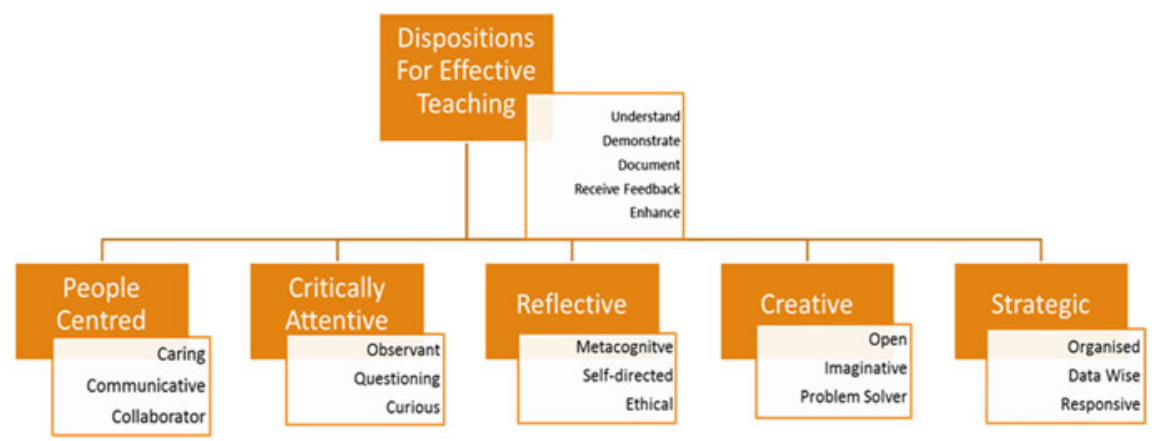

Fig. 5.1 The dispositions for effective teaching framework (Reprinted by permission from Springer, Teacher education: Innovation, intervention and impact by Brandenburg, R., McDonough, S., Burke, J., and S. White (Eds.), 2016)

dispositions identified in our framework. Our fortuitous involvement in the Staying BRiTE project (https://www.stayingbrite.edu.au/) led us to considering the connection between dispositions and resilience and so we developed a research project focused on PSTs' first teaching experience in order to see whether the dispositions acted as a resource for resilience.

\subsubsection{Teaching Values in Action}

As part of the site-based nature of our programme, we have a number of carefully constructed teaching and learning experiences that are designed to provide PSTs with the opportunity to understand the complexity of teaching and learning, and to apply theory in practice. One of these opportunities involved PSTs teaching in the Values in Action (VIA) (https://www.viacharacter.org/) programme in the partnership school where we teach site-based university classes. This was the first teaching experience for PSTs and they worked in co-teaching partnerships to plan, teach and evaluate three VIA lessons. The VIA programme was a new initiative within the school and all teachers taught lessons that had an explicit focus on understanding and using character strengths to foster learning and build growth mindsets. Like the school students, the PSTs completed the character strengths survey as a way of understanding their personal values.

This first teaching experience provided PSTs with an insight into the complexity of learning and teaching in an authentic school context and was challenging for a number of reasons. A key challenge was that the VIA programme was new to the school and there were varying levels of understanding about its nature and its value held by school leaders, teachers and students. The PSTs were in a co-teaching situation where they were working out-of-field teaching values, and where they have not established relationships with the school students. In their teaching, the PSTs 
were required to make theory-practice connections and to plan each session with a focus on differentiation. PSTs also dealt with organisational challenges in the school context such as rooms being changed, staff and students being absent, and interruptions to the planned programme. Our involvement in the Staying BRiTE (https://www.stayingbrite.edu.au/) project led us to embedding the BRiTE modules into a core course within the Master of Teaching programme and PSTs completed the modules during the weeks when this first teaching experience occurred. As we became more interested in the explicit teaching of resilience in teacher education, we wondered whether the dispositions in our framework could also act as a resource for building resilience. This teaching experience provided a good opportunity to examine this connection through research. Our guiding research question became: Does a focus on thinking dispositions enable resilience in challenging teaching and learning contexts? Being on-site with the students as they planned, taught and evaluated the VIA sessions enabled us to create opportunities for PSTs to use writing and dialogue to reflect in and on practice in order to surface what underlies judgements, the choice of strategies, feelings in certain situations, how problems are framed and resolved and so on (Schon 1983).

\subsection{Prompting Reflection on the Thinking Dispositions and Resilience}

As part of the Professional Learning Communities (PLC) course that PSTs complete in the programme, they create a reflective journal where they examine their learning and development across the first semester. Along with embedding the BRiTE modules throughout different weeks of the PLC course, we also provided students with journal prompts to encourage explicit reflection on the modules and their own developing understandings of resilience and the dispositions. In constructing the journal prompts, we were encouraging PSTs to look for the connections between the ways that the dispositions and their completion of the BRiTE modules might support their resilience in context. In Fig. 5.2, we provide an overview of these prompts and indicate when they occurred within the teaching and learning sequence of the PLC course.

\subsection{Our Research Approach}

While we developed a teaching and learning approach for embedding the BRiTE modules in the PLC course, we were also keen to research the process and to use that research to assist us in identifying how the dispositions and BRiTE modules might act as a resource for enabling the development of resilience in context. While all 21 students in the on-campus cohort participated in the VIA teaching sessions, 
Pre VIA teaching stage (having done the first BRITE module)

Draw resilience in the context of teaching.

What personal resources/ capacities/dispositions do you think resilient teachers draw on in teaching?

What sorts of challenges do you think you will face as you prepare for, teach and evaluate your

involvement in the VIA sessions?

What personal resources/capacities do you think you will need to draw upon during this experience?

\section{During the teaching phase of the VIA}

Reflect upon some of the challenges you are experiencing, how you are feeling during this experience and what is enabling you to cope.

\section{Post VIA teaching experience (having completed the BRiTE modules)}

Draw resilience in the context of teaching. Compare and contrast your two drawings.

What do you think the capacities /personal resources/dispositions of resilient teachers are?

What are you learning through this experience about teaching/student learning/school improvement/yourself?

Reflect on the Teaching Dispositions framework and which dispositions enabled you to learn during this experience.

Reflect on the connections between your experience and the BRITE modules.

Fig. 5.2 Journal prompts for the VIA/Resilience project

participation in the research element of the project was voluntary. Ethics approval was granted and PSTs were invited to participate in the research by an independent researcher who was not teaching the PSTs for the PLC course. The research approach drew on a primarily qualitative approach and used a range of data collection methods, with PSTs having the option to participate in some, or all, of the data collection methods.

\subsubsection{Data Collection Methods}

Data collected as part of the research included:

- Field notes taken by one researcher who observed the PLC classes during the VIA teaching experience.

- On-the-spot semi-structured interviews conducted before and after the VIA teaching experience $(n=11)$.

- PSTs' journal entries related to the VIA teaching experiences and to the BRiTE modules $(n=10)$.

- BRiTE user survey $(\mathrm{n}=14)$.

While we collected a range of data as part of our research approach, for this chapter, we are drawing on the data from the interviews, the journals and the BRiTE user survey. The first source is data collected from the on-the-spot interviews, with 11 of the PSTs volunteering to participate in the interview phases of the research. These interviews occurred directly after the PSTs taught their VIA sessions and were 
intended to capture their immediate thoughts about the resources and strategies that were enabling them to cope with the challenge of learning to teach. Question prompts for the interviews included questions such as "What is helping you to stay positive?" and "What are you finding challenging?" There were two interviews each conducted after the VIA teaching experiences and these interviews were audio recorded and transcribed for analysis.

The second data source we examine in this chapter is the BRiTE user survey, with 14 PSTs opting to complete this online survey. The survey contained 22 questions that included demographic information and Likert scale response items and openended questions. PSTs were asked to rate $(1=$ strongly disagree; $5=$ strongly agree) the modules (e.g. The modules have made me think about ways I can support my own resilience) and possible future uses (e.g. I will use the content from the modules in my teaching career). Open-ended questions prompted students to write about how they had applied their learning from the modules and encouraged them to articulate how they had made connections between the learning in the modules and experiences they had encountered.

The third data source we examine is the journal entries, completed by 10 of the PSTs. As outlined in Fig. 5.2, the prompts encouraged explicit reflection on the connections between the dispositions framework, the BRiTE modules and resilience.

\subsubsection{Data Analysis}

In analysing the interviews, we used narrative inquiry methods in order to construct narratives of the PSTs experiences as described in their interviews. We, each of us, independently coded the data looking for evidence of the thinking dispositions and for evidence of processes and outcomes related to resilience. We then came together to compare our analysis and to identify sentences from the interviews that were representative of the codes. In the next stage, we assembled narrative vignettes for each interview in order to highlight the complexity of the PSTs' experience. Further details about the analysis process and examples of these vignettes can be found in McGraw and McDonough (2019).

The journal entries were coded using an open coding process to identify evidence of the dispositions and of processes and outcomes related to resilience.

Analysis of the survey data was completed by separating the quantitative Likert scale data from the open-ended responses. Given the small sample $(n=14)$, percentages were calculated for the Likert scale survey items, and the open-ended questions, as per the interviews, were coded for evidence of the thinking dispositions. 


\subsection{Analysis and Discussion}

\subsubsection{The People-Centred Disposition as a Foundational Aspect Supporting Resilience}

On analysing the interview, survey and journal data, we identified the central role a people-centred thinking disposition played in enabling PSTs to be resilient in context (McGraw and McDonough 2019). Despite being faced with the challenge of teaching out-of-field, with a peer and with students they did not know, the PSTs demonstrated an orientation towards the students and the peer they were working with, that enabled them to be resilient despite the complexity of the work. Jordan's (2006) model of relational resilience suggests that mutual empathy, empowerment and courage are the "building blocks of resilience" (p. 79), and in the experiences of the PSTs we see the ways that a people-centred way of thinking enables relational resilience, as demonstrated by Penny who described an interaction with a student saying, "I tried to give him a bit of space and not harass him". In the analysis of the interview data we identified the ways that this people-centred disposition interconnects with the other thinking dispositions in order to enable PSTs to demonstrate resilience and problem-solving in challenging contexts (McGraw and McDonough 2019).

Similarly, there was evidence in the open-ended responses from the BRiTE user survey of PSTs engaging in people-centred thinking as they considered the role they would play in supporting the resilience of others, with one PST commenting that, "The modules made me aware that I'm good at judging other peoples' emotions and I can empathise strongly with other people" (\#4). The PST went on to state, "The modules have made me recognise that I need to be a contributor to this network too, so I will be mindful in the future to be supportive and caring to my colleagues and friends" (\#4).

This people-centred focus was also identified in the journal responses, with a focus on relationships with others enabling PSTs to consider the connection to wellbeing and resilience as illustrated in the following quote:

I have had some difficulties and have been amazed at the support I have received. My friends and family mean the world to me and it is important that I help my future students build their own resilience ... Community builds relationships and I hope students can be encouraged to become part of their own community. Wellbeing is connected to resilience and relationships. If you have these two you have wellbeing (\#1).

This focus on building relationships to support resilience was reflected throughout the journal entries, with PSTs drawing connections between this way of thinking and the ways that they can build resilience in the context of schooling:

The BRiTE modules have demonstrated strong connections to the VIA sessions. Building resilience does not come easy, and sometimes, you really do need to have that positive mindset in the tough challenges that teachers face daily. However, the environment and the context that we work and live in can play a huge role in facilitating resilience. Building relationships with students is something that was really important in the VIA sessions (\#5). 
PSTs reflected on their motivations for teaching in the journals, and the peoplecentred nature of their motivations are identified by PSTs as something that enables them to remain optimistic despite the challenges they face in learning to teach. PST \#8 describes that "I think the students will keep me going, some days will be good but you have to expect the bad days as well. The people around me will also motivate me to keep going".

\subsubsection{The Interconnected Nature of the Dispositions in Supporting Resilience}

While we identified the foundational nature of people-centred thinking to the resilience process, we also identified that PSTs also place a focus on engaging in reflective and strategic thinking in responding to the challenge of learning to teach. This interconnection between ways of thinking is identified in the interviews, survey and journal responses, and enables PSTs to be purposeful, optimistic and to solve problems in the context of learning to teach.

Analysis of the open-ended survey responses indicated that completion of the modules provided PSTs with the ability to activate the reflective thinking disposition, through which they became more self-aware. This is illustrated by the PST who commented that, "I have been able to reflect on my past experiences in instances where I haven't been resilient and learnt from these in conjunction with the modules" (\#10). Similarly, another PST remarked, "The modules reminded me to stand back and see the bigger picture and to take time off. When I am stressed it affects my mood and behaviour so it is important to take time out" (\#13). The use of reflective thinking enabled PSTs to be aware of the ways that they use strategies and resources that contribute to the development of resilience, as described by this PST, "It has been interesting to notice how many of the strategies I can apply to situations that I currently experience, and also think about how I could have applied them in past situations" (\#4).

The journal entries too, demonstrate evidence of the ways that PSTs are reflecting on, and identifying strategies that enable them to navigate the challenges of teaching. For one PST, "Learning about how to build relationships with colleagues, students and parents through a range of strategies and ways to look after yourself on placements and when you are a teacher were really important" (\#6). Another PST described being strategic in order to maintain a balance between work and university saying "I think it's very important to have a work life balance all throughout life. I complete most of my uni work during the week so I have the weekend to work and see my friends and family" (\#7). In reflecting on the strategies that they used to maintain a positive wellbeing, the PST identified the strategies they plan to use into their future career as a teacher. 


\subsubsection{PST Perceptions and Understandings of Resilience}

In analysing both the survey and journal data, we were interested to discover the ways that completion of the modules might work in conjunction with the dispositions framework to build PST perceptions and understandings of resilience.

The PSTs identified that completion of the modules had enabled them to develop and deepen their understandings of resilience with 79\% of PSTs agreeing or strongly agreeing to the prompt "The modules helped me develop my knowledge and skills". Most (84\%) participants agreed or strongly agreed that "The modules helped raise awareness about the skills I already have", with one PST commenting in the openended response that, "I know that I have a good combination of skills to be resilient-it is something I am very conscious of. I feel great after doing the modules" (\#6). The deepening of understandings of resilience after the completion of the modules was also reflected in the journals, with one PST describing the ways that considering resilience in the context of the VIA teaching experience was valuable:

It was one of those cases for me that I had heard of resilience before and thought about it a little, but not really as a teacher, more just from a self role. I liked that there was the acknowledgement that we can be resilient in different parts of our lives, with different things. I think we have the tendency to think we either are or not. It was knowing the theory, but doing the practice $(\# 1)$.

While $70 \%$ of the PSTs agreed or strongly agreed that the modules helped them "understand things I hadn't really thought about before", only 64\% agreed or strongly agreed to the prompt "The modules have made me think about ways I can support my own resilience". In response to this prompt, however, some identified being "already confident" (\#10) or that "I already had strategies and learnt nothing new" (\#1) that they could draw from to support their resilience. We identified that the completion of the BRiTE modules provided an opportunity for PSTs to reflect on their skills, capacities and their support networks. In similar ways to Mansfield et al. (2016), we also identified that some PSTs described the modules and the content as "common sense". This view was expressed despite "an acknowledgement that a review and reinforcement of the learnings and wisdoms was both timely and valuable" (Mansfield et al. 2016, p. 225).

PST \#1 aged in the 45-49-year-old bracket identified that the modules did not teach them anything that they had not gained through their past life experiences, however, for PSTs in the 20-24-year-old age bracket $(n=8)$, there was a greater recognition that the content of the modules was useful in developing their understandings. There were some small age-related differences between PSTs perceptions of the modules, and this suggests the need to consider how we might work with diverse PST cohorts to build their understandings of resilience, by enabling them to make connections between both their current and their past life experiences. 


\subsection{Conclusions and Future Directions}

Mansfield, Papatraianou, McDonough and King (2018) argue that "teacher educators require opportunities to engage in collective, shared professional learning about the resilience process and contextual approaches within teacher education programs that foster and support the development of pre-service teacher resilience" (p. 94). Through participation in the Staying BRiTE project, we have had the opportunity to engage in a collective network focused on exploring these contextual approaches to resilience in teacher education.

Through our research examining this work, we have been provided with an opportunity to explore how resilience might be supported in authentic teaching contexts through a focus on the thinking dispositions. The findings from the interview, survey and journal data indicated that the people-centred thinking disposition was foundational for PSTs and enabled them to demonstrate resilience in context, despite a challenging first teaching experience (McGraw and McDonough 2019). In the different forms of data, we were able to identify the ways that the dispositions framework and the completion of the BRiTE modules provided an opportunity for the PSTs to examine and reflect on their resilience process as they undertook the VIA teaching experience. The data suggest that the interconnection between the dispositions in the framework and the completion of the BRiTE modules supported the PSTs ability to be resilient in context.

While the data indicates that a focus on the thinking dispositions may act as a personal resource to support resilient outcomes in teaching, we need to continue to explore ways to make these thinking dispositions visible and to evaluate and explore the ways that they contribute to the resilience process. Coming to deeper understandings of the dispositions and of the ways that they support resilience processes and outcomes will provide those in teacher education with the opportunity to create meaningful and authentic learning opportunities for PSTs.

\section{References}

Bair, M. A. (2017). Identifying dispositions that matter: Reading for consensus using a Delphi Study. The Teacher Educator, 52(3), 222-234. https://doi.org/10.1080/08878730.2017.1315475.

Baggio, J. A., Brown, K., \& Hellebrandt, D. (2015). Boundary object or bridging concept? A citation network analysis of resilience. Ecology and Society, 20(2), 2. https://doi.org/10.5751/ES-07484200202.

Brandenburg, R., \& Gervasoni, A. (2016). Images of teaching: Discourses within which pre-service teachers construct their professional identity as a teacher upon entry to teacher education courses. In R. Brandenburg, S. McDonough, J. Burke, \& S. White (Eds.), Teacher education: Innovation, intervention and impact (pp. 117-138). Singapore: Springer.

Buckworth, J. (2017). Unstated and unjust: Juggling relational requirements of professional experience for pre-service teachers. Asia-Pacific Journal of Teacher Education, 45(4), 369-382. https:// doi.org/10.1080/1359866X.2017.1335853.

Costa, A., \& Kallick, B. (2000). Habits of mind: A developmental series. Alexandria, VA: Association for Supervision and Curriculum Development. 
Costa, A., \& Kallick, B. (2014). Dispositions: Reframing teaching and learning. Thousand Oaks, California: Corwin.

Day, C., \& Gu, Q. (2014). Resilient teachers, resilient schools: Building and sustaining quality in testing times. Oxon, UK: Routledge.

Diez, M. (2007). Assessing dispositions: Context and questions. In M. E. Diez \& J. Raths (Eds.), Dispositions in teacher education (pp. 183-201). Charlotte, NC: Information Age Publishing.

Entwistle, N. (2012). The quality of learning at university: Integrative understanding and distinctive ways of thinking. In J. R. Kirby \& M. J. Lawson (Eds.), Enhancing the quality of learning: Dispositions, instruction, and learning processes (pp. 15-31). New York: Cambridge University Press.

Francis, A. T., Olson, M., Weinberg, P. J., \& Stearns-Pfeiffer, A. (2018). Not just for novices: The programmatic impact of practice-based teacher education. Action in Teacher Education, 40(2), 119-132. https://doi.org/10.1080/01626620.2018.1424053.

Freeman, L. (2007). An overview of dispositions in teacher education. In A. E. Diez \& J. Raths (Eds.), Dispositions in teacher education (pp. 3-29). Charlotte, North Carolina: Information Age Publishing.

Grant-Smith, D., \& Gillett-Swan, J. (2017). Managing the personal impact of practicum: Examining the experience of Graduate Diploma in Education students. In J. Nuttall, A. Kostogriz, M. Jones, \& J. Martin (Eds.), Teacher education policy and practice: Evidence of impact, impact of evidence (pp. 97-112). Singapore: Springer.

Hazel, G. (2018). Finding a place for resilience in teacher preparation. In M. Wosnitza, F. Peixoto, S. Beltman, \& C. F. Mansfield (Eds.), Resilience in education: Concepts, contexts and connections (pp. 221-235). Singapore: Springer.

Jenset, I. S. (2018). Researching practice-based teacher education: Trends, challenges and recommendations for future research. Acta Didactica Norge, 12(3), 1-23. https://doi.org/10.5617/adno. 5933.

Jordan, J. (2006). Relational resilience in girls. In S. Goldstein \& R. Brooks (Eds.), Handbook of resilience in children (pp. 73-86). New York: Springer.

Mansfield, C. F., Beltman, S., Price, A., \& McConney, A. (2012). "Don't sweat the small stuff:" Understanding teacher resilience at the chalkface. Teaching and Teacher Education, 28, 357-367. https://doi.org/10.1016/j.tate.2011.11.001.

Mansfield, C. F., Beltman, S., Broadley, T., \& Weatherby-Fell, N. (2016). Building resilience in teacher education: An evidence informed framework. Teaching and Teacher Education, 54, 77 87. https://doi.org/10.1016/j.tate.2015.11.016.

Mansfield, C. F., Papatraianou, L., McDonough, S., \& King, L. (2018). Building resilience in times of uncertainty and complexity: Teacher educator perceptions of pre-service teacher resilience. In D. Heck \& A. Ambrosetti (Eds.), Teacher education in and for uncertain times (pp. 83-98). Singapore: Springer.

McGraw, A., Dresden, J., Gilberston, E., \& Baker, M. (2017). Site-based teacher education as a context for attending to the complexity and person-centred nature of teaching and learning: A narrative inquiry involving teacher educators from Australia and the United States. In J. Nuttall, A. Kostogriz, M. Jones, \& J. Martin (Eds.), Teacher education policy and practice-Evidence of impact, impact of evidence (pp. 51-65). Singapore: Springer.

McGraw, A., \& McDonough, S. (2019). Thinking dispositions as a resource for resilience in the gritty reality of learning to teach. The Australian Educational Researcher, 46(4), 589-605. https:// doi.org/10.1007/s13384-019-00345.z.

McGraw, A., McDonough, S., Wines, C., \& O’Loughlan, C. (2016). Activating teaching dispositions in carefully constructed contexts: Examining the impact of classroom intensives. In R. Brandenburg, S. McDonough, J. Burke, \& S. White (Eds.), Teacher education: Innovation, intervention and impact. Singapore: Springer.

Mies, R., \& Knipe, S. (2018). "I sorta felt like I was out in the middle of the ocean": Novice teachers' transition to the classroom. Australian Journal of Teacher Education, 43(6), 105-121. https://doi. org/10.14221/ajte.2018v43n6.7. 
Perkins, D. N., \& Ritchhart, R. (2004). When is good thinking? In D. Y. Dai \& R. J. Sternberg (Eds.), Motivation, emotion and cognition: Integrative perspectives on intellectual functioning and development (pp. 351-384). Mahwah, NJ: Erlbaum.

Pooley, J. A., \& Cohen, L. (2010). Resilience: A definition in context. The Australian Community Psychologist, 22(1), 30-37.

Ritchhart, R. (2002). Intellectual character: What it is, why it matters, and how to get it. San Franscisco, CA: Jossey-Bass.

Riveros, A., Norris, S. P., Hayward, D. V., \& Phillips, L. M. (2012). Dispositions and the quality of learning. In J. R. Kirby \& M. J. Lawson (Eds.), Enhancing the quality of learning: Dispositions, instruction and learning processes (pp. 32-50). NY: Cambridge University Press.

Schon, D. A. (1983). The reflective practitioner: How professionals think in action. USA: Basic Books.

Teacher Education Ministerial Advisory Group. (2014). Action now: Classroom ready teachers. Canberra, Australia: Australian Government.

Väisänen, S., Petarinen, J., Pyhältö, K., Toom, A., \& Soini, T. (2018). Student teachers' proactive strategies for avoiding study-related burnout during teacher education. European Journal of Teacher Education, 41(3), 301-317. https://doi.org/10.1080/02619768.2018.1448777.

Vartuli, S., Snider, K., \& Holley, M. (2016). Making it real: A practice-based early childhood teacher education program. Early Childhood Education Journal, 44, 503-514. https://doi.org/10.1007/ s10643-015-0733-2.

Zeichner, K. (2012). The turn once again towards practice-based teacher education. Journal of Teacher Education, 63(5), 376-382. https://doi.org/10.1177/0022487112445789.

Open Access This chapter is licensed under the terms of the Creative Commons Attribution 4.0 International License (http://creativecommons.org/licenses/by/4.0/), which permits use, sharing, adaptation, distribution and reproduction in any medium or format, as long as you give appropriate credit to the original author(s) and the source, provide a link to the Creative Commons license and indicate if changes were made.

The images or other third party material in this chapter are included in the chapter's Creative Commons license, unless indicated otherwise in a credit line to the material. If material is not included in the chapter's Creative Commons license and your intended use is not permitted by statutory regulation or exceeds the permitted use, you will need to obtain permission directly from the copyright holder.

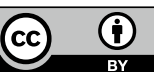

